\title{
Significant Shortening of Leukocyte Telomere Length in Korean Patients with Bipolar Disorder 1
}

\author{
Eun-Jeong Joo ${ }^{1,2}$, Yong Min Ahn ${ }^{3,4,5}$, Mira Park ${ }^{6}$, Soon Ae Kim ${ }^{7}$ \\ ${ }^{1}$ Department of Neuropsychiatry, School of Medicine, Eulji University, Daejeon, ${ }^{2}$ Department of Psychiatry, Nowon Eulji Meical Center, Eulji \\ University, ${ }^{3}$ Department of Neuropsychiatry, Seoul National University Hospital, ${ }^{4}$ Department of Psychiatry and Behavioral Science, ${ }^{5}$ Institute \\ of Human and Behavioral Medicine, Seoul National University College of Medicine, Seoul, Departments of ${ }^{6}$ Preventive Medicine and \\ ${ }^{7}$ Pharmacology, School of Medicine, Eulji University, Daejeon, Korea
}

\begin{abstract}
Objective: Telomere shortening has been seen in major psychiatric disorders, including major depressive disorder. However, only a few small studies have examined this in bipolar disorder (BD). We compared the telomere length in patients with BD1 or BD2 with that in matched healthy controls.

Methods: We included 215 patients with BD (128 BD1, 87 BD2) and 204 age- and sex-matched healthy controls. Relative telomere length was determined by quantitative polymerase chain reaction. The patients and controls were compared separately for age groups, sex, and BD subgroups (BD1 and BD2).

Results: We found significant telomere shortening in patients with BD1 $(p<0.001)$, but not in patients with BD2. In male patients with BD1, the 30-39 year age group had significant shortening of telomere length than controls $(p=0.01)$. Female patients with BD1 in the 19-29-year age group had significantly shortened telomeres compared to the controls $(p<0.01)$.

Conclusion: Our results suggest a significant reduction in telomere length in BD1. Telomere shortening would be a potential biomarker for BD.
\end{abstract}

KEY WORDS: Bipolar disorder; Female; Biomarker; Telomere.

\section{INTRODUCTION}

In humans, telomeres are composed of multiple copies of the non-coding nucleotide sequence TTAGGG. Telomeres protect chromosome ends against DNA loss and become shorter with each cell division due to incomplete telomere replication [1]. Telomeres can be rebuilt by telomerase by adding small DNA fragments to the lagging DNA strand during mitosis. Telomere length is determined by both innate genetic factors and epigenetic influences [2]. Telomere shortening occurs with repeated cell division and reflects cell aging. It is influenced by many biological

Received: August 3, 2020 / Revised: November 23, 2020

Accepted: November 27, 2020

Address for correspondence: Soon Ae Kim

Department of Pharmacology, School of Medicine, Eulji

University, 77, Gyeryong-ro 771 beon-gil, Jung-gu, Daejeon

34824, Korea

E-mail: sakim@eulji.ac.kr

ORCID: https://orcid.org/0000-0002-9831-0511 process, including exposure to inflammation [3] or oxidative stress, persistently raised stress hormones, and the availability of telomerase [4]. Telomere shortening causes cell damage and malfunction and is associated with many medical conditions, including major psychiatric illnesses such as schizophrenia, bipolar disorder (BD), and major depressive disorder $[5,6]$.

A possible biological mechanism for the association between telomere length and psychiatric illness has been suggested: the regeneration of neural stem and progenitor cells could be reduced by cell death due to telomere shortening [7]. Another hypothesis is that aged immune cells secrete pro-inflammatory cytokines, which cause inflammation and then trigger oxidative stress and telomere shortening [8]. A recent meta-analysis and reviews confirmed that major depressive disorder shows accelerated aging and shortening of telomere length in peripheral blood cells [6].

However, only a few papers have examined BD. Here,

(ㄷ) This is an Open-Access article distributed under the terms of the Creative Commons Attribution Non-Commercial License (http://creativecommons.org/licenses/by-nc/4.0) which permits unrestricted non-commercial use, distribution, and reproduction in any medium, provided the original work is properly cited. 
we report additional evidence of a possible association between $\mathrm{BD}$ and telomere length.

\section{METHODS}

We enrolled 128 patients with BD1, 87 with BD2, and 204 healthy age- and sex-matched controls with informed consent. The participants were recruited from the psychiatric outpatient departments of Eulji Meical Center and other university hospitals in Seoul, Korea. Each patient was diagnosed by consensus by at least two psychiatrists based on the criteria of the Diagnostic and Statistical Manual of Mental Disorders, Fourth Edition. Patients with a traumatic brain injury, intellectual disability, current substance-related disorder, neurocognitive disorder, or psychiatric disorder due to another medical condition were excluded. Through a matching process using a pool of control subjects previously developed by our study group, age- and sex-matched controls were selected for the BD1 and BD2 groups. Relative telomere length ( $\mathrm{T} / \mathrm{S}$ ratio) was determined by quantitative polymerase chain reaction (qPCR) with considering previous study [9]. In brief, the quantification cycle $(\mathrm{Ct})$ of the telomeric region and the Ct of a single-copy gene (36B4) were assessed via the telomeric and single-copy gene specific qPCR. To check PCR efficiency, we drew a standard curves for each age group, which were created by serial dilutions of age matched control DNAs. Telomere length assay for all samples were performed in triplicate. Detailed information is provided in the Supplementary Table 1 (available online).

The three groups were compared using an analysis of variance and an analysis of covariance to control age and sex. To adjust for the effects of aging on telomere length, comparisons were done for each age group. This study protocol was approved by the ethics committee of Nowon Eulji Medical Center, Eulji University (IRB\# 2016-08-009).

\section{RESULTS}

There was a significant difference in telomere length among the BD1, BD2, and control groups $(p<0.001)$. Post-hoc analysis found that the BD1 patients had significantly shorter telomeres than the healthy controls, while the BD2 patients did not differ from the controls. There was a significant difference between BD1 and BD2. In a subgroup analysis by sex, both males and females had a significant difference among the three groups ( $p=0.003$ for males, $p<0.001$ for females). Post-hoc analysis found that BD1 patients differed significantly from BD2 patients and healthy controls. The telomere length was shortest in BD1 and longest in the controls (Table 1). In an analysis of age groups, females with BD1 who were aged 19-29 years had the most significant telomere shortening $(p<0.01)$. Although the telomere shortening in males with BD1 who were aged $19-29$ years was not significant $(p=0.09)$, it tended to be shorter. Instead, males with BD1 who were aged $30-39$ years had significantly shorter telomeres than matched controls $(p=0.01)$. BD2 patients who were aged $19-29$ years did not show any significant telomere shortening compared to the healthy controls (Table 2).

\section{DISCUSSION}

We found a significant telomere shortening for BD1 as

Table 1. Comparison of telomere length among the BD1, BD2, and control groups

\begin{tabular}{|c|c|c|c|c|c|c|}
\hline Sex & Diagnosis & Number & Mean & SD & F (adjusted F) & $p$ value (adjusted $p$ value) \\
\hline \multirow[t]{3}{*}{ Total } & BD1 & 128 & 0.677 & 0.836 & $9.821(13.55)^{\mathrm{a}}$ & $<0.001(<0.001)^{\mathrm{a}}$ \\
\hline & BD2 & 87 & 1.026 & 0.945 & & \\
\hline & Control & 204 & 1.029 & 0.573 & & \\
\hline \multirow[t]{3}{*}{ Male } & BD1 & 68 & 0.847 & 1.005 & $1.88(6.07)^{b}$ & $0.155(0.003)^{b}$ \\
\hline & BD2 & 40 & 1.179 & 1.147 & & \\
\hline & Control & 101 & 0.994 & 0.59 & & \\
\hline \multirow[t]{3}{*}{ Female } & BD1 & 60 & 0.483 & 0.536 & $18.301(18.10)^{b}$ & $<0.001(<0.001)^{b}$ \\
\hline & BD2 & 47 & 0.896 & 0.719 & & \\
\hline & Control & 103 & 1.063 & 0.558 & & \\
\hline
\end{tabular}

BD1, bipolar disorder 1; BD2, bipolar disorder 2; SD, standard deviation.

${ }^{\mathrm{a}}$ Adjusted by sex and age. ${ }^{\mathrm{b}}$ Adjusted by age. 
Table 2. Comparison of telomere length between patients and controls according to age

\begin{tabular}{|c|c|c|c|c|c|c|}
\hline Diagnosis & Sex & Age group (yr) & Number & Control & Patient & $p$ value \\
\hline \multirow[t]{5}{*}{ BD1 } & Male & Total & 68 & $0.94 \pm 0.54$ & $0.85 \pm 1.00$ & 0.01 \\
\hline & & $19-29$ & 29 & $0.56 \pm 0.22$ & $0.44 \pm 0.38$ & 0.09 \\
\hline & & $30-39$ & 18 & $1.07 \pm 0.71$ & $0.73 \pm 0.38$ & 0.01 \\
\hline & & $40-49$ & 13 & $1.17 \pm 0.43$ & $0.98 \pm 0.88$ & 0.19 \\
\hline & & $>50$ & 8 & $1.40 \pm 0.21$ & $2.41 \pm 1.96$ & 0.21 \\
\hline \multirow[t]{5}{*}{ BD1 } & Female & Total & 60 & $1.18 \pm 0.65$ & $0.48 \pm 0.54$ & $<0.01$ \\
\hline & & $19-29$ & 42 & $1.22 \pm 0.70$ & $0.37 \pm 0.43$ & $<0.01$ \\
\hline & & $30-39$ & 4 & $0.62 \pm 0.24$ & $0.32 \pm 0.15$ & 0.15 \\
\hline & & $40-49$ & 4 & $0.99 \pm 0.41$ & $0.55 \pm 0.12$ & 0.15 \\
\hline & & $>50$ & 10 & $1.30 \pm 0.53$ & $1.01 \pm 0.80$ & 0.17 \\
\hline \multirow[t]{5}{*}{ BD2 } & Male & Total & 40 & $1.11 \pm 0.67$ & $1.18 \pm 1.15$ & 0.43 \\
\hline & & $19-29$ & 25 & $0.65 \pm 0.24$ & $0.82 \pm 0.63$ & 0.94 \\
\hline & & $30-39$ & 9 & $1.77 \pm 0.47$ & $1.99 \pm 1.67$ & 0.63 \\
\hline & & $40-49$ & 6 & $1.86 \pm 0.55$ & $1.47 \pm 1.41$ & 0.36 \\
\hline & & $>50$ & 0 & NA & NA & NA \\
\hline \multirow[t]{5}{*}{ BD2 } & Female & Total & 47 & $0.90 \pm 0.33$ & $0.90 \pm 0.72$ & 0.53 \\
\hline & & $19-29$ & 38 & $0.93 \pm 0.32$ & $1.00 \pm 0.72$ & 0.62 \\
\hline & & $30-39$ & 1 & 1.4 & 1.93 & NA \\
\hline & & $40-49$ & 4 & $0.69 \pm 0.23$ & $0.31 \pm 0.07$ & 0.02 \\
\hline & & $>50$ & 4 & $0.73 \pm 0.37$ & $0.26 \pm 0.17$ & 0.04 \\
\hline
\end{tabular}

Values are presented as number only or mean \pm standard deviation.

BD1, bipolar disorder 1; BD2, bipolar disorder 2; NA, not available.

a whole as well as both in males and females separately. This result is consistent with a recent meta-analysis, which found a significantly shorter leukocyte telomere in BD [10]. In male group, most subjects were in 19-29 and $30-39$ age groups and 30-39 age group showed significant telomere shortening than control group. Female 19-29 age group had most subjects and showed significant difference from control group. No gender difference was found in our study.

An effect of disease on telomere length was observed especially in young subjects, but not older subjects. Similarly, in major depressive disorder, the results were usually negative in elderly patients, probably because there was no control for vascular pathologies or late-life medical conditions [11]. We did not include those information, either. In another study, contrary to our results, significant reductions in telomere length were found in both early and late BD [12]. Besides inconsistencies of findings, insufficient and different number of samples in each age group in our study made it difficult to consider the age as a crucial factor in determining leukocyte length in BD. Further studies with enough sample size for the whole range of age and controlling for physical conditions including vascular pathologies are needed.

We could not find significant shortening of leukocyte telomere length in BD2. Contrasting our results, there was a study reported a trend to telomere shortening in BD2 [13]. As the published studies have been relatively small and rarely have differentiated BD1 and BD2, it is difficult to speculate specific reasons why BD1 and BD2 are different in telomere length at this point. Since BD2 has different clinical features from BD1, more studies on this issue would contribute to finding biological difference between BD1 and BD2.

Several studies revealed a wide range of cognitive disturbances during acute mood episodes and significant impairment in declarative memory during remission [14]. $\mathrm{BD}$ is thought to be associated with fronto-limbic-subcortical circuit abnormalities, and functional imaging studies suggest that abnormal hippocampus activation related to emotional, attentional, and memory tasks in BD [15]. Hippocampal morphology was associated with telomere length $[16,17]$ and hippocampal volume and delayed recall was positively associated with telomere length. A shorter telomere length reflected a smaller hippocampal volume and more impaired delayed recall [18]. Recently, it is suggested that telomere shortening could represent a mechanism that moderates the proliferative capacity of human hippocampal progenitors, which may subsequently impact on human cognitive function and 
psychiatric disorder pathophysiology [19]. However, it is unclear whether telomere shortening is a risk factor or the result of cumulative exposure to disease [20]. For example, Henje Blom et al. [21] suggested that shortening of telomere length and reduction of hippocampal volume are already present in early-onset major depressive disorder from a study with adolescent depression patients.

The limitations of this study should be considered when interpreting our results. First, since our data did not include clinical information other than the psychiatric diagnosis, we could not analyze the dose-response relationship for the degree of telomere shortening and severity of BD such as lifetime duration of the mood disorder, duration of a poorly or untreated mood disorder, number of episodes of mood disorder, and treatment response. Second, there are many potential confounders in the interpretation of telomere length. In peripheral blood, leukocyte age varies. Theoretically, this causes varying leukocyte telomere lengths. In addition, methods to measure telomere length are not stable. Third, more variables such as early and recent life adversity, psychological resiliency, lifestyle factors, and latent active viral infection [22-25] other than age, sex can influence leukocyte telomere length. We could not control them in this study. Fourth, we should consider psychiatric comorbidities such as anxiety and substance use disorder [26,27], as well as medical illnesses $[28,29]$. Heavy alcohol use itself is associated with telomere shortening [30], and psychiatric medications can influence telomere length $[31,32]$. Since we could not collect other clinical information, we could not analyze the influence of environmental factors, psychiatric and medical comorbidities, or psychiatric treatment.

Here, we have added more evidence of a positive association between $\mathrm{BD} 1$ and telomere shortening. Additional studies with more subjects covering all ages and studies that explore the clinical meaning of telomere shortening are necessary.

\section{Acknowledgments}

We thank Ms. Eun Hye Jang for helping with the quantitative PCR experiments. This research was supported by the Bio and Medical Technology Development Program of the National Research Foundation, funded by the Korean government, MSIP (no. 2016M3A9B6904240, 2016M3A9B6904241, 2016M3A9B4904244).

\section{Conflicts of Interest}

No potential conflict of interest relevant to this article was reported.

\section{Author Contributions}

Conceptualization, Funding: Soon Ae Kim, Eun-Jeong Joo. Data acquisition and analysis: Yong Min Ahn, Soon Ae Kim. Writing - original draft: Eun-Jeong Joo. Writingreview \& editing: Eun-Jeong Joo, Yong Min Ahn, Mira Park, Soon Ae Kim.

\section{ORCID}

Eun-Jeong Joo

https://orcid.org/0000-0001-8766-8713

Yong Min Ahn https://orcid.org/0000-0002-4458-797X

Mira Park https://orcid.org/0000-0003-3827-9089

Soon Ae Kim https://orcid.org/0000-0002-9831-0511

\section{REFERENCES}

1. Zhu Y, Liu X, Ding X, Wang F, Geng X. Telomere and its role in the aging pathways: telomere shortening, cell senescence and mitochondria dysfunction. Biogerontology 2019;20:1-16.

2. Müezzinler A, Zaineddin AK, Brenner H. A systematic review of leukocyte telomere length and age in adults. Ageing Res Rev 2013;12:509-519.

3. Zhang J, Rane G, Dai X, Shanmugam MK, Arfuso F, Samy RP, et al. Ageing and the telomere connection: an intimate relationship with inflammation. Ageing Res Rev 2016;25:55-69.

4. Barnes RP, Fouquerel E, Opresko PL. The impact of oxidative DNA damage and stress on telomere homeostasis. Mech Ageing Dev 2019;177:37-45.

5. Darrow SM, Verhoeven JE, Révész D, Lindqvist D, Penninx BW, Delucchi KL, et al. The association between psychiatric disorders and telomere length: a meta-analysis involving 14,827 persons. Psychosom Med 2016;78:776-787.

6. Muneer A, Minhas FA. Telomere biology in mood disorders: an updated, comprehensive review of the literature. Clin Psychopharmacol Neurosci 2019;17:343-363.

7. Liu L. Linking telomere regulation to stem cell pluripotency. Trends Genet 2017;33:16-33.

8. Cai Z, Yan LJ, Ratka A. Telomere shortening and Alzheimer's disease. Neuromolecular Med 2013;15:25-48.

9. Fries GR, Bauer IE, Scaini G, Wu MJ, Kazimi IF, Valvassori SS, et al. Accelerated epigenetic aging and mitochondrial DNA copy number in bipolar disorder. Trans/ Psychiatry 2017;7: 1283.

10. Huang YC, Wang LJ, Tseng PT, Hung CF, Lin PY. Leukocyte telomere length in patients with bipolar disorder: an updated meta-analysis and subgroup analysis by mood status. Psychiatry Res 2018;270:41-49. 
11. Schaakxs R, Verhoeven JE, Oude Voshaar RC, Comijs HC, Penninx BWJH. Leukocyte telomere length and late-life depression. Am J Geriatr Psychiatry 2015;23:423-432.

12. Barbé-Tuana FM, Parisi MM, Panizzutti BS, Fries GR, Grun LK, Guma FT, et al. Shortened telomere length in bipolar disorder: a comparison of the early and late stages of disease. Braz J Psychiatry 2016;38:281-286.

13. Elvsåshagen T, Vera E, Bøen E, Bratlie J, Andreassen OA, Josefsen $\mathrm{D}$, et al. The load of short telomeres is increased and associated with lifetime number of depressive episodes in bipolar II disorder. J Affect Disord 2011;135:43-50.

14. Martínez-Arán A, Vieta E, Colom F, Reinares M, Benabarre A, Gastó C, et al. Cognitive dysfunctions in bipolar disorder: evidence of neuropsychological disturbances. Psychother Psychosom 2000;69:2-18.

15. Frey BN, Andreazza AC, Nery FG, Martins MR, Quevedo J, Soares JC, et al. The role of hippocampus in the pathophysiology of bipolar disorder. Behav Pharmacol 2007; 18:419-430.

16. King KS, Kozlitina J, Rosenberg RN, Peshock RM, McColl RW, Garcia CK. Effect of leukocyte telomere length on total and regional brain volumes in a large population-based cohort. JAMA Neurol 2014;71:1247-1254.

17. Nilsonne G, Tamm S, Månsson KN, Åkerstedt T, Lekander M. Leukocyte telomere length and hippocampus volume: a meta-analysis. F1000Res 2015;4:1073.

18. Powell TR, Dima D, Frangou S, Breen G. Telomere length and bipolar disorder. Neuropsychopharmacology 2018:43:445-453.

19. Palmos AB, Duarte RRR, Smeeth DM, Hedges EC, Nixon DF, Thuret $\mathrm{S}$, et al. Telomere length and human hippocampal neurogenesis. Neuropsychopharmacology 2020;45:2239-2247.

20. Verhoeven JE, van Oppen P, Révész D, Wolkowitz OM, Penninx BW. Depressive and anxiety disorders showing robust, but non-dynamic, 6-year longitudinal association with short leukocyte telomere length. Am J Psychiatry 2016;173: 617-624.

21. Henje Blom E, Han LK, Connolly CG, Ho TC, Lin J, LeWinn $\mathrm{KZ}$, et al. Peripheral telomere length and hippocampal volume in adolescents with major depressive disorder. Trans/ Psychiatry 2015;5:e676.
22. Ridout KK, Levandowski M, Ridout SJ, Gantz L, Goonan K, Palermo D, et al. Early life adversity and telomere length: a meta-analysis. Mol Psychiatry 2018;23:858-871.

23. Verhoeven JE, van Oppen P, Puterman E, Elzinga B, Penninx BW. The association of early and recent psychosocial life stress with leukocyte telomere length. Psychosom Med 2015; 77:882-891.

24. Mayer SE, Prather AA, Puterman E, Lin J, Arenander J, Coccia $\mathrm{M}$, et al. Cumulative lifetime stress exposure and leukocyte telomere length attrition: the unique role of stressor duration and exposure timing. Psychoneuroendocrinology 2019;104: 210-218.

25. Bellon M, Nicot C. Telomere dynamics in immune senescence and exhaustion triggered by chronic viral infection. Viruses 2017;9:289.

26. Hoen PW, Rosmalen JG, Schoevers RA, Huzen J, van der Harst P, de Jonge P. Association between anxiety but not depressive disorders and leukocyte telomere length after 2 years of follow-up in a population-based sample. Psychol Med 2013:43:689-697.

27. Navarro-Mateu F, Husky M, Cayuela-Fuentes P, Álvarez FJ, Roca-Vega A, Rubio-Aparicio M, et al. The association of telomere length with substance use disorders: a systematic review and meta-analysis of observational studies. Addiction 2020. doi: 10.1111/add.15312. [Epub ahead of print]

28. Zhan Y, Hägg S. Telomere length and cardiovascular disease risk. Curr Opin Cardiol 2019;34:270-274.

29. Tamura Y, Takubo K, Aida J, Araki A, Ito H. Telomere attrition and diabetes mellitus. Geriatr Gerontol Int 2016;16 Supp/ 1:66-74.

30. Yamaki N, Matsushita S, Hara S, Yokoyama A, Hishimoto A, Higuchi S. Telomere shortening in alcohol dependence: roles of alcohol and acetaldehyde. J Psychiatr Res 2019;109:27-32.

31. Squassina A, Pisanu C, Congiu D, Caria P, Frau D, Niola P, et al. Leukocyte telomere length positively correlates with duration of lithium treatment in bipolar disorder patients. Eur Neuropsychopharmacol 2016;26:1241-1247.

32. Monroy-Jaramillo N. Analyzing leukocyte telomere length in bipolar disorder. Braz J Psychiatry 2017;39:274. 